\title{
A VIL(D)A EM PRETO
}

(Conta-se que entre 1700 e 1801 foram extraídos na região deVila Rica cerca de 615.00o quilos de ouro, de um total brasileiro de 983.000 quilos no mesmo período e cerca de 3 milhões de quilates de diamantes)

I
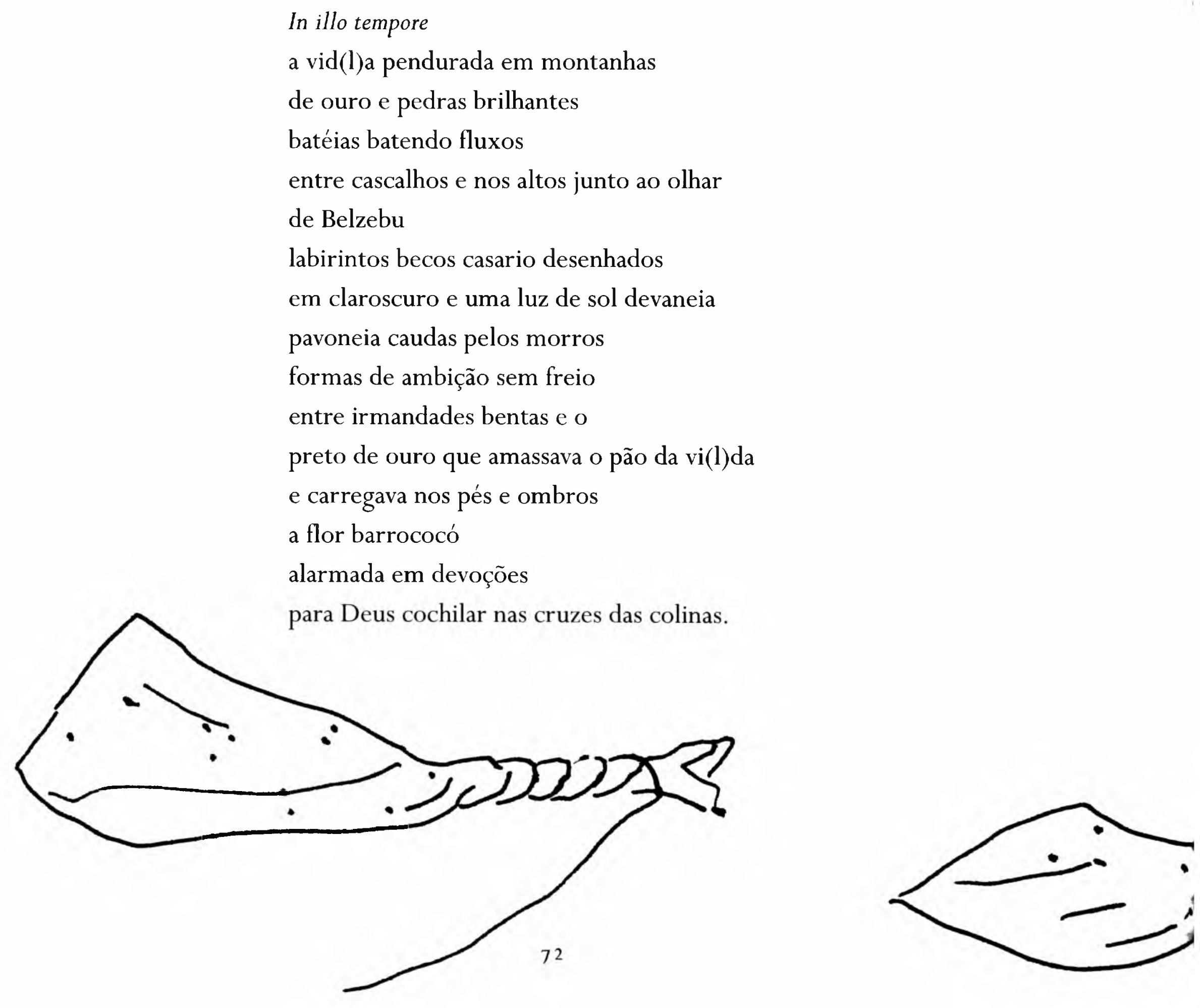
Num tempo amarelo

a pedra sabão subia volutas cômoros pontões

ourivesaria de sapos e muriçocas

nos vôos junto ao queixo de anjos e santos

agudas barroquidades em labirintos desurbanos

onde casas de almas mal lavadas

em janelas quadradinhas

e grossas portas maciças com fechos e guizos e dobradiças de ferro bruto

e pedras que ao sol brilhavam no interior das pupilas

soavam fantasmagorias negras

nos oráculos e oratórios de cedro e ouro.

As orações subiam aos céus

nos caminhos montanhosos do ouro diamantoso

que não ia a Londres.

III

Ruas de labirintos erectos

nos ombros desdobrados dos becos

e velhas alimárias de cascos lascados

moventes lerdas nos pés-de-moleque

ouviam negros tocar berrante

e conduzir

o dourado da ambição

— pepitas e pedrinhas _

em santos-do-pau-oco.

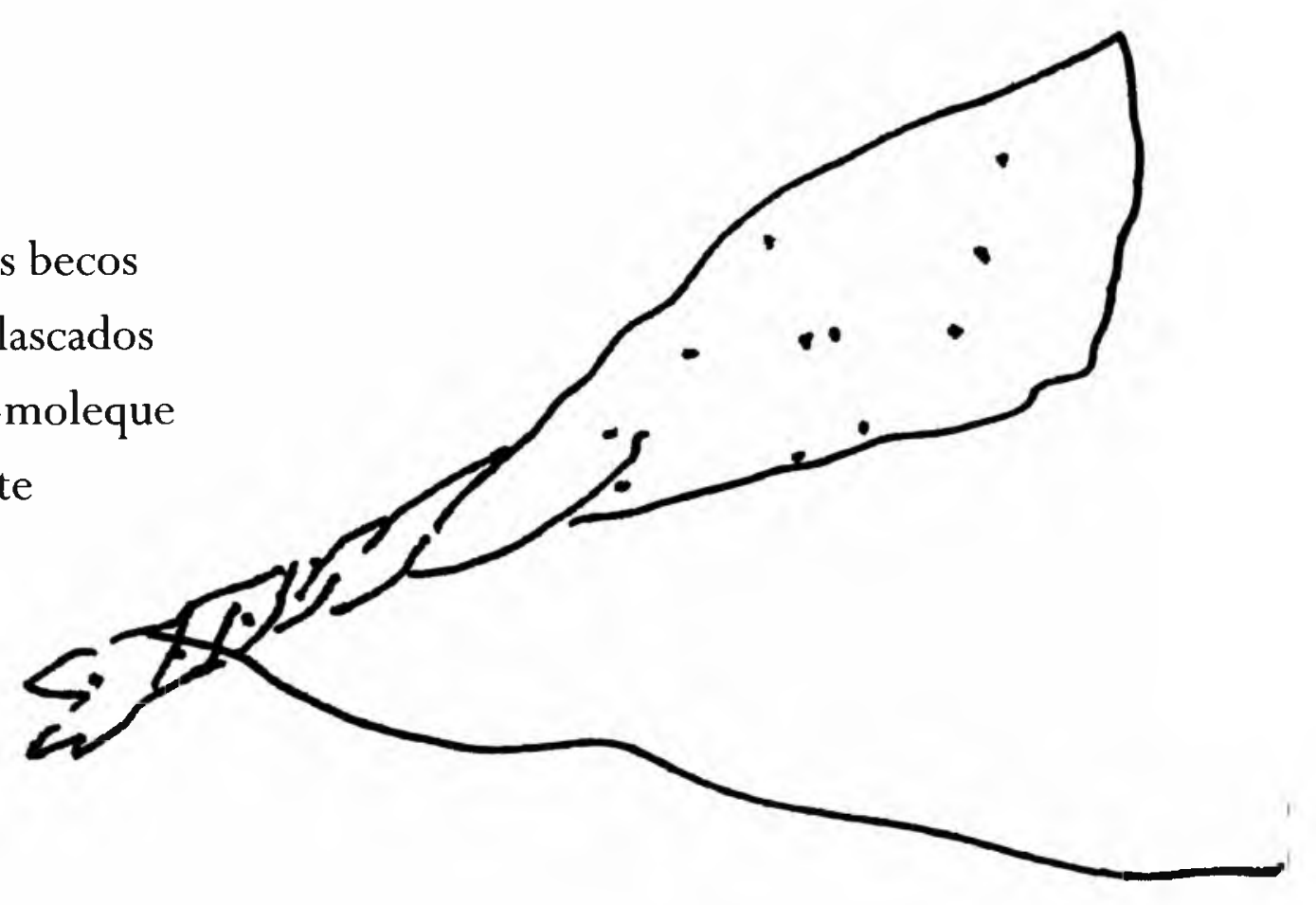


A multitude das vozes moderninhas

fedia ecos longínquos

sem consciência do suor negro que carregou

pedras sem conta e toneladas de ouro e

ergueu altares e templos

a santos brancos e barrocosos

porque essas vozes-ruídos não vêem-ouvem que

em cada beco pedra janela barro torre cruz

cruzeiro sino oratório altar escadaria porta

madeira batéia templo casa solar

e o infinito sobrado

como máscara máscara máscara

dos simulacros simulacros

há uma África debruçada

com a cabeça entre os joelhos.

A lira de Dirceu, Marília, desafinou o pastor alçado ao átrio do Rosário de São Francisco do Pilar; cofia, Marília, as barbas do Tiradentes ouvindo a sentença fatal de D. Maria a Louca o que permanece da flor machucada de ouro do mito encravado nos morros de onde o ouro escorreu; há, Marília, uma alegria disparatada que secciona os passos trôpegos do passado 
e as asas pouco assíduas do futuro;

com a doce indiferença amarelada, Marília, do olhar turístico

que nada vê além dos simulacros

já que o sangue do trabalho de outrora

ruinoso dos homens encangalhados

virou moda, Marília.

Seu pastor artroso no bordão,

ninfa do Carmo esgotado, bordeja morros

na solidão de pedras pretas, desafinado,

de lira rouca em punho, gasoso e estéril.

VI

Há sim uma lógica que preside o fio

de labirintos e becos desencontrados:

é a geometria da trilha

que outrora levava os homens

para o frágil destino que os incinerava

no estatuto do ouro e do brilhante e do ferro e da pedra sabão;

as casas precárias de arquitetura oscilante

guardavam

almas cintilantes entre a burocracia e a escravidão;

Tomás, Joaquim José, Maciel, Cláudio, Silvério e os padres

milhões de padres podres

dançavam nus sobre ombros de negros

— quais nomes mazumbas, muzambas, minas, quimbundos sobraram? 
e os carapinhas, almocreves, artífices, artesãos

(gentes sem fim de tantas artes e ofícios)

queriam ir para o céu;

a harpa estava desafinada

mas as pedras sobrepostas ficaram em pé

e a lira rangeu versos e versos e versos de a-m-o-r.

VII

A colônia rugia o sangue fervente

de seus impasses de processo de morte

e a morte rondava com a roda da rosa-dos-ventos

extraindo ouro do ventre negro das rochas

e as rochas movidas relviam nas relvas

as vísceras vazias

e as vísceras roncavam o rude espasmo

dum ouro derradeiro

e o ouro era a roda rubicunda

que cravava igrejas templos casinholas solares

como farpas fatais no fígado dos homens;

era ouro preto em fantasmagorias da Vila Rica

mas o ouro nunca é negro senão quando

no couro ativo do africano flui. 


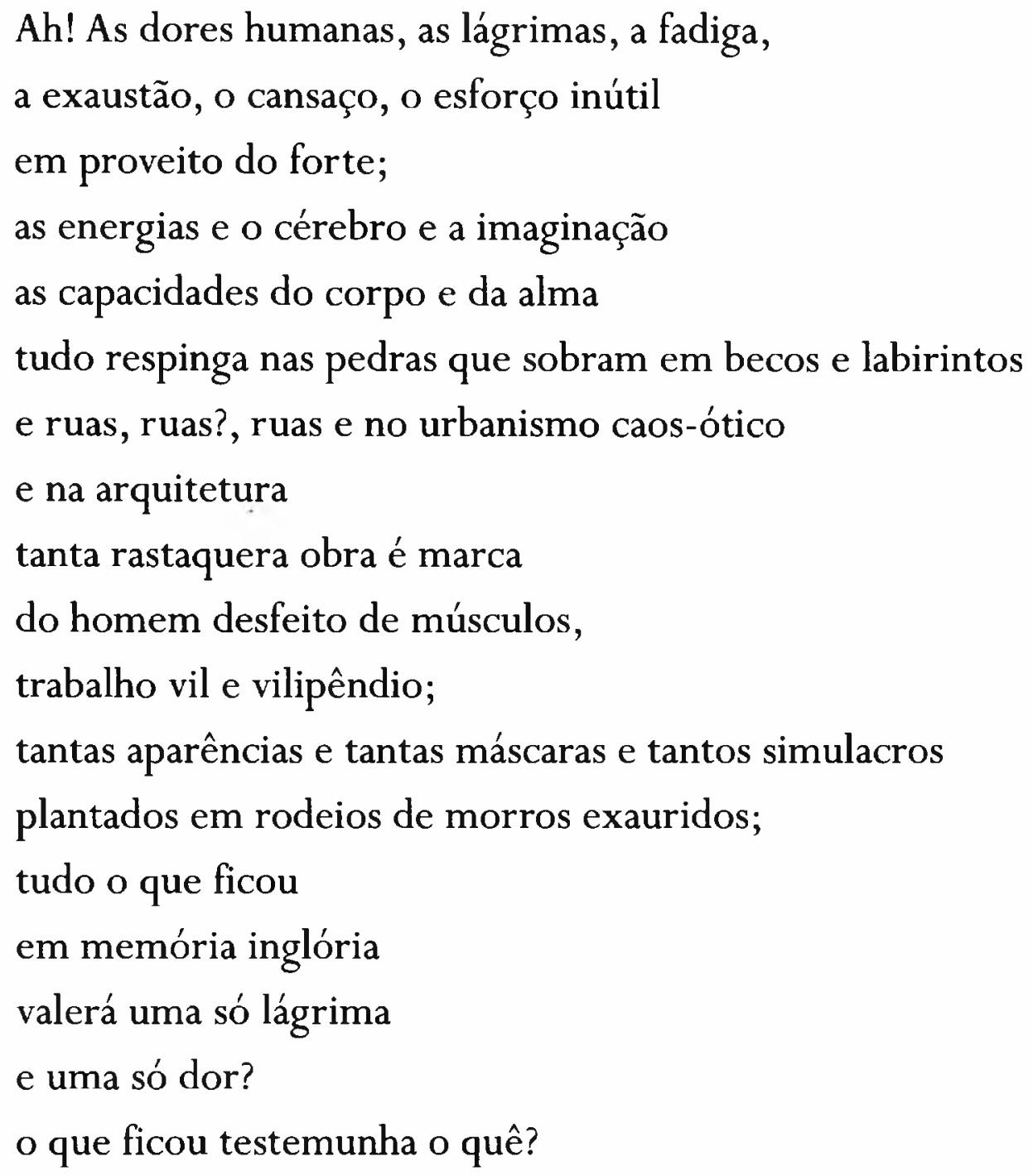

(Textos escritos em Ouro Preto, 24.7.97, Café Gerais, Rua Direita, I 22 ) Dedicados a Célia, garçonete moreninha, que cedeu papel e caneta e cervejas.

Valentim Facioli 